presence of the sea. Water has always been an 'unpredictable element', and early Man took care 'not to settle too close to it, preferring to retreat to the higher ground, or at least to near-by dunes. Eventually, he built houses on stilts in the water, used rubble to construct artificial mounds in the sea, and learned how to tame the waters with the help of dams and new embankments. In time he even learned how these dams and dikes could be used to hold back the sea itself, providing new and fertile land for farming and protecting himself from floods.

Until recently, Europe's river-banks and coastal landscapes were shaped mainly by two flood phenomenarivers in spate and flood-tides at sea. From source to estuary, river-banks were constantly altered by the silt and floating debris carried down from the mountains and hills, while the coastline itself was repeatedly reshaped by ocean-currents and tides. Animals and plants took advantage of these changes, becoming adapted to meet them. Man, on the other hand, took them as a challenge and, after many reverses, succeeded in defeating themonly to end as often the ultimate loser.

The fuller extent of Man's losses became evident as the rivers lost their power to resist pollution, water supplies were endangered, extensive tracts of agricultural and grazing lands became parched, and the recreational potential of the few remaining untouched areas was threatened. These warning signs did not go unheeded. Agreements were reached on the discharge of waste into rivers and on ways of preventing oil-pollution; proposals were made to restrict industrial concentration, and supraregional schemes were devised to control building development along rivers and on coasts. On the Rhine, for example, proposals were made for reopening sections of the river which had previously been closed off, linking them up to form a new river system. Indeed, the variety and range of the problems in different regions is only equalled by the variety and range of the proposals and programmes put forward to solve them!

One thing missing so far, however, has been energetic implementation of those schemes for the improvement and future protection of river-banks and coastlines. This is where the new Council of Europe campaign comes in. It calls on politicians, specialists, and conservation groups, to take action to protect these particularly endangered and vulnerable parts of our natural environment-and also on every individual to ensure, by his personal conduct, that no further damage is done.

What exactly is at stake? The coastal cliffs of Europe, for example, house the continent's largest bird colonies and must be protected against intrusion and oil-spillage. Similarly, the broad mud-flats and the estuaries of nearly all the rivers of Europe are of international importance as nurseries for vital species of fish and as resting places for millions of migratory birds. The main aim here must be to ensure that the long-projected conservation programmes are actually implemented. Along coasts and rivers, comprehensive protection has still to be provided for such waterside areas as have not so far been overrun by the recreation industry. Nearly all of the few remaining tracts of riverside forest are in danger-as are the plants and animals which they shelter and nourish. Whenever it is technically possible, new banks - with appropriate native grasses, forbs, and trees-should be laid out between dikes, dams, and the open water. Boat-owners and surfers must take care not to harm these new plantations, and anglers, hunters, and hikers, can all help to preserve the resting, feeding, and breeding, areas of the wildlife which thrives on river-bank and sea-shore.

Long ago, when the sailors, merchants, and colonists, of old set sail for new shores, this meant a new beginning. Today, our remaining shores and river-banks are no longer new, but old and vulnerable. Nonetheless, we can all make a new beginning by helping to save these places before it is too late.

HENRY MAKOWSKI
c/o Directorate of Press and Information
Council of Europe Secretariat General
BP 431 R6
67006 Strasbourg Cedex
France.

HENRY MAKowski Council of Europe Secretariat General 67006 Strasbourg Cedex France.

\title{
What of The Sea Tomorrow?
}

The whole range of marine sciences came under review at a European Oceanography Colloquy held in Strasbourg, France, from 19 to 22 June 1983 . The hundred or so specialists at the Colloquy endorsed a plan to set up a European Association of Marine Science and Technology Laboratories, under the auspices of the Council of Europe Parliamentary Assembly.

International cooperation in scientific research and the training of specialists is a precondition of understanding the sea and its resources, and of discovering how to make use of them without upsetting the balance of Nature. Various fields of enquiry were suggested for Europe: deep-water research techniques, the North Atlantic, the South Seas and the Antarctic, the coastal fringe, and exploitation and protection of Mediterranean resources. Noteworthy practical suggestions included the United
Kingdom's proposal to set up a research centre at the University of Stirling, Scotland, to study fish diseases.

Some provisions of the United Nations Convention on the Law of the Sea are so ambiguous, it was noted, that they 'might lead to an outright ban on scientific research', and to avoid this danger participants also proposed that the Council of Europe examine the possibility of drawing up a European regional convention, supplementary to the UN Convention, to remove obstacles to freedom of scientific marine research.

European INFORMATION CENTRE FOR NATURE
CONSERVATION
BP 431 R6
67006 Strasbourg Cedex
France.

European Information CENTRE for NATURE $B P 431 R 6$ France.

\section{Birds that Abandoned Christmas Island Now Returning}

Some six months after they abandoned Christmas Island, the birds were beginning to return to that midPacific atoll, according to Dr Ralph W. Schreiber, the ornithologist who discovered in the autumn of 1982 that almost the entire bird population of the Island about 17 millions-had disappeared. 
Curator of Ornithology at the Natural History Museum of Los Angeles County in California, Dr Schreiber returned for 10 days in June of this year to the island just north of the Equator, to survey the bird population. The survey, financed by the National Science Foundation and The National Geographic Society, is part of a long-term research project on the biology of tropical seabirds, especially as they are affected by the tropical disturbance of the ocean and atmosphere known as El Niño.*

Dr Schreiber found that individuals of most of the 18 species that mysteriously disappeared have returned in small numbers. However, three of the species - the Black or White-capped Noddy (Anous minutus), the Crested Tern (Thalassius bergii), and the Lesser Frigatebird (Fregata oriel) -are breeding in numbers that approach the Island's population prior to the fall of 1982 when the mass abandonment started.

The birds feed exclusively on small fishes and squids which live in the surrounding Pacific Ocean. Earlier this year Dr Schreiber had attributed the mass abandonment to El Niño and the drastic changes it had caused in oceanic and atmospheric conditions which caused the fish population to leave the area, but still he cannot say what the future holds for the birds on the island: 'Ocean and atmosphere scientists are unsure of future directions for the El Niño conditions, and cannot now predict what will happen to the birds in coming months,' Dr Schreiber said. 'The recovery of the bird populations depends on the food supply in the waters surrounding the island.' $\dagger$

* See the account by Professor Klaus Wyrtki of 'Investigation of the El Niño Phenomenon in the Pacific Ocean', published in Environmental Conservation, 2(4), pp. 281-2, 1975.- Ed
Christmas Island, the world's largest coral atoll, is part of the Republic of Kiribati and includes about 200 square miles (518 sq. $\mathrm{km}$ ) of terrain. It is so named because it was discovered on Christmas Eve in 1777 by the English navigator Captain James Cook. The island has a human population of between 1,500 and 2,000 .

\section{RalPH KaZARIAN \\ National Science Foundation $1800 \mathrm{G}$ Street \\ Washington \\ DC 20550, USA.}

\begin{abstract}
†In response to our enquiries, Dr Schreiber wrote most interestingly (in litt. 8 August 1983): ' $\mathrm{El}$ Niño is a recurring phenomenon and I suspect that the birds are adapted to the disappearance of their food. The publicity about our finding the birds gone last fall was a bit sensational. While adults abandoning their young to starve may be sad at first thought, the survival value to the species is evident, and will become more so as we continue to follow up on what is going on. It looks [as though] individual birds have been able to find fish and are starting to breed again. Individual selection seems to be working and this should make Mr Darwin happy.... Three weeks later Dr Schreiber wrote us again: 'We will be going back [to Christmas Island] in October and again in January, March, and June 1984, and are hoping... to continue to follow the situation for the next 3-5 years. We believe this "warm event" is an extremely valuable biological experiment that provides insight into the biological bottlenecks which animal populations must go through. It is now preliminarily obvious that some individuals are able to find food even in times of food stress for the whole population, and that individual selection does operate. It will be most interesting to see what happens over the coming years with the populations which are greatly reduced at present.'-Ed.
\end{abstract}

\section{Energy Conservation in the Third World: Recommendations of a Workshop}

The United Nations Environment Programme (UNEP) convened an International Workshop on Energy Conservation in Developing Countries in the Palais des Nations, Geneva, from 21-25 November 1983. The Workshop was attended by experts from Abu Dhabi, Argentina, Brazil, Denmark, Ecuador, Egypt, Finland, France, India, Indonesia, Iraq, Japan, Nigeria, Switzerland, Thailand, USSR, United Arab Emirates, UK, and USA. There were also participants from the Economic Commission for Europe (ECE), the Economic Commission for Western Asia (ECWA), and the Food and Agriculture Organization (FAO).

UNEP presented a draft report to the Workshop on the experience of both developed and developing countries in energy conservation and the measures taken by these countries in that respect. Participants also considered the potential of energy conservation in the Third World, and the environmental, social; and economic, aspects of energy conservation. They agreed that a considerable potential for energy conservation exists in developing countries. Many of these countries were not aware of the contribution that energy conservation might make to their development. Energy conservation schemes would enable developing countries to achieve more than otherwise with their resources, or to achieve their development targets at less cost. Implementation of such schemes would also contribute to the fight against poverty.
The key to the situation lay in integrating energy conservation in overall development plans, rationalizing the use of energy sources, supporting these efforts by adequate legislative and institutional frameworks, providing energy users with an energy-pricing strategy to eliminate waste, allocating funds for investment in, and incentives to, energy efficiency improvements, and establishing programmes of promotion and education as well as information systems to increase awareness of the relevance and importance of energy conservation.

The meeting recommended energy conservation measures in various economic sectors, industry, the buildings and residential sector, transport, agriculture, and power generation. In studying financial constraints, participants emphasized that with the help of effective educational programmes and improved house-keeping, maintenance, and minor reprofiting actions, considerable savings could be achieved in the short term.

General energy conservation measures and action, it was agreed, have positive environmental impacts. However, the environmental aspects of some new technologies for energy conservation should be studied, taking into consideration the prevailing conditions in the Third World.

P.S. When the above official piece was in press we received, from a participant of the Workshop, a first-hand account for which we hope to find space in the Conferences \& Meetings section of our Spring 1984 issue.-Ed. 